\section{Sterbehilfe heute}

\section{Eric Hilgendorf}

Die demographische Entwicklung, der medizinisch-technologische Fortschritt und das zunehmende Verlangen nach Selbstbestimmung auch am Lebensende führen dazu, dass Rechtsfragen der Sterbehilfe in den letzten Jahren erheblich an Bedeutung gewonnen haben. Die Möglichkeit, auch über das eigene Sterben entscheiden zu können, bildet nach heutigem Verständnis einen wesentlichen Bestandteil der Patientenrechte am Lebensende. Allerdings klaffen Theorie und Praxis nicht selten auseinander. Umso wichtiger ist die rechtwissenschaftliche Klärung grundlegender Wertungen, Konzepte und Unterscheidungen; für eine rationale Debatte der anstehenden Fragen ist sie unumgänglich.

Unter ,Sterbehilfe“ versteht man, einem Definitionsvorschlag Claus Roxins folgend, eine Hilfe, die einem schwer erkrankten Menschen auf seinen Wunsch oder doch zumindest im Hinblick auf seinen mutmaßlichen Willen geleistet wird, um dem Betroffenen einen seinen Vorstellungen entsprechenden menschenwürdigen Tod zu ermöglichen. Legt man diese Begriffsbestimmung zugrunde, so gehören auch menschliche Zuwendung und medizinische Basisversorgung am Lebensende zur Sterbehilfe. Strafrechtliche Fragen werfen sie kaum auf. Viel problematischer sind Handlungen, die die verbleibende Lebenszeit verkürzen. Man unterscheidet dabei üblicherweise lebenszeitverkürzendes aktives Handeln von Unterlassungen, die lebenszeitverkürzend wirken. Ein aktives Tun ist strafbar, wenn es mit Tötungsabsicht durchgeführt wird. Steht allerdings für den Täter die Schmerzlinderung im Vordergrund, so soll die Tat nach Ansicht des BGH gerechtfertigt sein (sog. indirekte Sterbehilfe). Dagegen ist ein Unterlassen nur dann strafbar, wenn auf der Seite des Unterlassenden eine Garantenstellung bestanden hat, die allerdings vom Patienten aufgehoben werden kann. Sterbehilfe in Form eines Unterlassens ist deshalb in aller Regel nicht strafbar. Ein Behandlungsabbruch umfasst neben Elementen des Unterlassens fast immer auch Momente aktiven Tuns. Umso bemerkens-

Prof. Dr. phil. Dr. iur. Eric Hilgendorf,

Alte Universität,

Domerschulstraße 16, 97070 Würzburg, Deutschland werter ist es, dass der $\mathrm{BGH}$ in seiner jüngeren Rechtsprechung dazu übergegangen ist, Behandlungsabbrüche dann für straflos zu erklären, wenn sie sich auf einen eindeutigen Patientenwillen stützen lassen. Viele Detailprobleme dieser Rechtsprechung sind noch zu klären, vor allem ihre Vereinbarkeit mit dem (fragwürdig gewordenen) Grundsatz, dass selbst der Rechtsgutsinhaber nicht über sein Leben verfügen darf.

Beihilfe zum Suizid, auch zum Patientensuizid, ist im Grundsatz nicht strafbar. Dies folgt aus dem Fehlen einer tatbestandsmäßigen Haupttat, denn der Suizid unterfällt in Deutschland keinem Straftatbestand. Der Gesetzgeber hat allerdings Dezember 2015 im neuen $\$ 217$ StGB eine Strafbarkeit von geschäftsmäßig geleisteter Beihilfe zum Suizid eingeführt. Er wollte damit in erster Linie Sterbehilfevereinigungen wie Dignitas oder Sterbehilfe Deutschland treffen, die seit Jahren Patienten mit schweren Erkrankungen durch Rat und Tat bei Suiziden unterstützen. Bedauerlicherweise hat der Gesetzgeber übersehen, dass durch die in $\$ 217$ StGB gewählten Formulierungen zentrale Bereiche der Palliativ- und Hospizmedizin ebenfalls in den Anwendungsbereich des neuen $\$ 217$ StGB hineingezogen werden. Ärzte handeln im ärztlichen Kontext immer geschäftsmäßig. Dem Wortlaut nach unterfallen deshalb z.B. auch die Verschreibung von schmerzlindernden, in hohen Dosen aber tödlichen Medikamenten oder die Überweisung in ein "Sterbezimmer", in welchem sich ein Patient durch Sterbefasten selbst zu Tode bringen kann, dem objektiven Tatbestand des $₫ 217$ StGB. Bislang ist es der Strafrechtswissenschaft nicht gelungen, eine allgemein konsentierte einschränkende Interpretation dieser schon wegen der genannten „Kollateraleffekte“ verfehlten und geradezu schädlichen Strafnorm zu entwickeln.

Die vom Unterzeichner veranstaltete Würzburger Tagung zum Recht der Sterbehilfe hatte es sich zur Aufgabe gemacht, die wichtigsten mit Sterbehilfe verbundenen Fragestellungen $\mathrm{zu}$ analysieren und Vorschläge zu ihrer Lösung zu entwickeln. Die Beiträge sind in dem vorliegenden Sonderheft versammelt. Ich danke allen Autorinnen und Autoren für ihre hervorragenden Texte und dem Schriftleiter der Zeitschrift „Medizinrecht“, Herrn Kollegen Katzenmeier, für den Abdruck. 